\title{
In-silico study of flavonoids from Cassia tora as potential anti-psoriatic agent
}

\author{
Ibezim Akachukwu*, Ezechukwu Emmanuel Amara \\ Department of Pharmaceutical and Medicinal Chemistry, University of Nigeria, Nsukka, Nigeria.
}

\begin{tabular}{|c|c|}
\hline ARTICLE INFO & ABSTRACT \\
\hline Received on: 15/08/2018 & \multirow{4}{*}{$\begin{array}{l}\text { Psoriasis is a skin disease that affects } 2 \%-3 \% \text { of the world's population. As a shift from the popular focus on plant } \\
\text { fatty acid, } 15 \text { flavonoids from Cassia tora were evaluated in-silico for their ability to bind to } 15 \text { anti-psoriatic targets. } \\
\text { It was observed that all the flavonoids made varying degrees of favorable binding interactions with each of the protein } \\
\text { targets. London dG scoring method identified that five compounds had a higher binding affinity toward tumor necrosis } \\
\text { factor- } \alpha \text {, Bruton's tyrosine kinase, peptidyl arginine deiminases, and spleen protein kinase than their co-crystallized } \\
\text { ligands. Twelve of the flavonoids made better binding interactions with } \mathrm{AA}_{2} \mathrm{R} \text {, PK, and protein kinase } \mathrm{C} \text { than their } \\
\text { co-crystallized inhibitors, whereas all the compounds except } 6 \text { had lower free binding energy toward P38MK, } \\
\text { interleukin (IL)-17A, phosphodiesterase- } 4 \text {, cathepsin S, and Jak- } 3 \text { than their native ligands. Only the docking scores } \\
\text { of three molecules (1, 2, and } 8 \text { ) ranked lower than the reference ligands of S1PR and Rac1. Moreover, it was noted } \\
\text { that only two interacted with IL- } 23 \text { with a binding affinity comparable to its native ligand. The docking scores of the } \\
\text { studied flavonoids highlight the presence of a highly polar group (especially sugar) as a vital structural requirement } \\
\text { for strong binding with the target proteins. }\end{array}$} \\
\hline $25 / 11$ & \\
\hline 2019 & \\
\hline $\begin{array}{l}\text { Key words: } \\
\text { Psoriasis, Cassia tora, } \\
\text { flavonoids, docking, drug- } \\
\text { likeness, binding interaction. }\end{array}$ & \\
\hline
\end{tabular}

\section{INTRODUCTION}

Psoriasis is a chronic, proliferative, and inflammatory skin disease affecting $2 \%-3 \%$ of the world's population (Griffiths and Barker, 2007). Psoriasis is one of the most baffling and persistent of skin disorders. It is usually characterized by red plaques with white scales. This is caused by skin cells which multiply up to 10 times faster than normal. As underlying cells reach the skin's surface and die, their sheer volume causes raised, red plaques covered with white scales (Bowcok, 2005; Cathrine and Prabavathi, 2011). Psoriasis typically occurs on the knees, elbows, and scalp, and it can also affect the torso, palms, and soles of the feet (Tollefson et al., 2018). Many searches for a

\section{"Corresponding Author}

Ibezim Akachukwu, Department of Pharmaceutical and Medicinal Chemistry, University of Nigeria, Nsukka, Nigeria. E-mail: akachukwu.ibezim@unn.edu.ng plant phytochemical with an anti-psoriatic effect have focused largely on the fatty acid compound class. Fatty acid is credited to exhibit anti-psoriatic activity by limiting the synthesis of leukotrienes (Christopher and Steny, 1993). However, the work by Vijayalakshmi and Madhira (2014) suggests flavonoids could as well possess chemotherapeutic potency towards psoriasis. Both topical and systemic drugs like betamethasone, tofacitinib, methotrexate, and so on are only used to manage the disease at each time it surfaces (Tollefson et al., 2018). Therefore, there is a need for a new anti-psoriatic agent.

Cassia tora is a legume from the Caesalpinioideae plant family. It grows wildly in tropical areas and though, it is considered as a weed, many studies have reported that its phytochemical constituent possesses interesting pharmacological properties ranging from antibacterial, antipsoriatic, and antifungal properties (Kim et al., 2004; 2015; Shukla et al., 2018; Vijayalakshmi and Madhira, 2014). In this current study, we have employed in silico technique because of its cost and time effectiveness. A collection 
of flavonoids from Cassia tora were assessed for drug-likeness and tested for their ability to interact with 15 validated antipsoriatic protein targets with the aim to discover more flavonoids from Cassia tora with possible anti-psoriatic effect and their likely mechanism of action.

\section{MATERIALS AND METHODS}

\section{Data collection}

The plant metabolites from Cassia tora which are of flavonoid compound class were retrieved from the literature sources comprising mainly of published articles from 2004 to 2015. The exact chemical structures of the flavonoids were confirmed from the Dictionary of Natural Products (Taylor and Francis, 2018). Although all the flavonoids were found in DNP, the small dataset was developed independent of DNP library.

\section{Evaluation of Lipinski parameters for drug-likeness}

Graphical user interface of the molecular operating environment (MOE) (Chemical Computing Group Inc., 2010) software was used to generate the three-dimensional molecular structures of the flavonoids and was energy minimized using molecular mechanics MMFF94 force field (Halgren, 1996) to an energy gradient of $0.001 \mathrm{kcal} / \mathrm{mol}$. The $3 \mathrm{D}$ flavonoids were saved as in $\mathrm{mol}^{2}$ format include into an MOE database (.mdb) file which is suitable for use in several virtual screening workflow protocols. The molar weight (MW), number of rotatable bonds (NRBs), lipophilicity $(\log \mathrm{P})$, hydrogen bond acceptor/donor (HBA/HBD), and Lipinski violations were calculated using the molecular descriptor calculator included in the QuSAR module of the MOE package.

\section{Docking simulation}

The crystal structures of the anti-psoriasis protein targets under review with their co-crystallized inhibitor were downloaded from protein data bank (Berman et al., 2000). The enzyme-inhibitor complexes were prepared according to standard for use in docking calculation (Ntie-Kang et al., 2014). For each complex, the co-crystallized water molecules and small nonessential molecules were removed. The protonate $3 \mathrm{D}$ procedure implemented in MOE was used to protonate the retained targetligand complexes, after which they were energy minimized using the Gromacs 4.5.5 ffG53a6 (Scott et al., 1999). The protein targets and co-crystallized ligands were subsequently separated and saved separately. The docking of all the flavonoids toward the binding site of the 15 antipsoriatic targets was carried out using the MOE Dock tool. Three main stages were involved in the docking process: Conformational Analysis of ligands, Placement, and Scoring. In the ligand Conformational Analysis stage, conformations from a single 3D conformation input ligand were generated by conducting a systematic search methodology. All combinations of angles were created for each ligand. During the Placement stage, a collection of poses was generated from the pool of ligand confirmations using the Triangle Matcher placement method. Several poses were generated by superimposition of ligand atom triplets and triplet points in the receptor binding site. The receptor sites points are composed of alpha sphere centers, representing locations of tight packing. At each iteration, a random conformation was selected; a random triplet of ligand atoms and a random triplet of alpha sphere centers were used to determine the pose. At the Scoring stage, the poses generated during the Placement stage were scored using the London $\mathrm{dG}$ scoring method. The London $\mathrm{dG}$ scoring function estimates the free energy of binding of the ligand from a given rotational and translational entropy terms, energy lost as a result go the flexibility of the ligand, hydrogen bonding, metal contacts, and a desolvation term due to the volumes of the atoms of the protein and ligand in contact with the solvent. Docking validation was an attempt to identify the best docking parameters which reproduce the ligand conformation (docking poses) within the binding pocket, i.e., having the lowest root mean square deviation (RMSD) values with respect to the experimental binding mode (X-ray crystal structure). During the docking validation procedure, the native ligands present within the binding pocket of each of the protein complexes were docked toward their respective receptions sites using different grid parameters. The parameters retained with the lowest RMSD values were then used to carry out docking for the data set toward the binding site of the 15 antipsoriatic drug targets.

\section{RESULTS AND DISCUSSION}

This current work was spurred from the study made by Vijayalakshmi and Madhira (2014) which found out that three flavonoids from Cassia tora exhibited the anti-psoriatic effect. This appeared to be a shift from the usual search for anti-psoriatic candidates in fatty acid plant class. Therefore, we made a collection of flavonoids isolated from Cassia tora spanning from 2004 to 2015. The two-dimensional chemical structures of the flavonoids with their names are shown in Figure 1.

\section{Physicochemical properties of the flavonoids}

Nowadays, assessment of the oral bioavailability profile of potential drug candidates at an early stage of drug discovery

Table 1. Physicochemical parameters of the flavonoids from Cassia tora.

\begin{tabular}{|c|c|c|c|c|c|c|}
\hline Codes & MW & HBA & HBD & $\log P$ & LV & NRB \\
\hline 1 & 448.38 & 11 & 7 & -0.003 & 2 & 4 \\
\hline 2 & 478.36 & 13 & 8 & -0.033 & 2 & 4 \\
\hline 3 & 430.40 & 9 & 4 & 0.807 & 0 & 5 \\
\hline 4 & 270.24 & 5 & 3 & 1.896 & 0 & 1 \\
\hline 5 & 252.22 & 4 & 1 & 2.678 & 0 & 1 \\
\hline 6 & 208.21 & 2 & 0 & 2.964 & 0 & 0 \\
\hline 7 & 270.24 & 5 & 3 & 2.482 & 0 & 0 \\
\hline 8 & 492.43 & 12 & 6 & -0.200 & 2 & 5 \\
\hline 9 & 446.40 & 10 & 5 & 0.118 & 0 & 4 \\
\hline 10 & 330.29 & 7 & 3 & 2.312 & 0 & 2 \\
\hline 11 & 358.34 & 7 & 1 & 2.343 & 0 & 4 \\
\hline 12 & 344.31 & 7 & 2 & 2.327 & 0 & 3 \\
\hline 13 & 284.26 & 5 & 2 & 2.631 & 0 & 1 \\
\hline 14 & 284.26 & 5 & 2 & 2.746 & 0 & 1 \\
\hline 15 & 284.22 & 6 & 3 & 2.095 & 0 & 1 \\
\hline
\end{tabular}


is done to maximize resources (Ibezim et al., 2015). Lipinski proposed a rule, now generally known as the "Lipinski rule of five (ro5)" which is often employed to investigate drug-likeness of drug candidates. He proposed that a compound has to have: less than five HBDs, less than 10 HBAs, a molecular weight of less than $500 \mathrm{Da}$, and a partition coefficient $\log P$ of less than 5 , in order to be drug-like. Potential drug candidates which violate two or more of the rule could possess bioavailability problems. Therefore, the set of molecular descriptors used by Lipinski were calculated, as shown in Table 1. Twelve out of the fifteen dataset violated none of the Lipinski rule. It was observed that three compounds failed to comply by the rule by outshooting the number of HBA and HBD criteria. Subsequently, this drastically lowers they lipophilic profile. Therefore, the three compounds may have problems with permeating across the cell membrane layers (Darvas et al., 2002). Be that as it may, this lipophilicity feature could be an advantage given that psoriasis is a skin disease. Hence, the inability of the drugs to pass/absorb through the skin will increase its concentration at the required site of action (skin surface) when applied topically.<smiles>O=c1cc(-c2ccc(O)c(O)c2)oc2cc(OC3OC(CO)C(O)C(O)C(O)C3O)cc(O)c12</smiles>

luteolin-7-O-beta-glucopyranoside (1)<smiles>O=C(O)CC(O)C(O)CC(Oc1c(-c2ccc(O)c(O)c2)oc2cc(O)cc(O)c2c1=O)C(O)O</smiles>

Quercetin-3-O-beta-D-glucuronide (2)<smiles>COc1ccc(-c2cc(=O)c3ccc(OC(O)C(O)C4COC(CO)C(O)C4O)cc3o2)cc1</smiles>

formononetin-7-O-beta-glucoside (3)<smiles>O=C1c2cccc(O)c2C(=O)c2c(O)cc(CO)cc21</smiles>

Aloe-emedin (4)<smiles>O=C(O)c1ccc2c(c1)C(=O)c1ccccc1C2=O</smiles>

Anthraquinone-2-carboxylic acid (5)<smiles>COc1c(O[C@@H]2C[C@H](CO)[C@@H](O)[C@H](O)[C@H]2O)c(C)cc2c1C(=O)c1c(O)cccc1C2=O</smiles>

Guco-obtusifolin (9)

Anthraquinone (6) Emedin (7)<smiles>COc1c(O[C@@H]2O[C@H](CO)[C@@H](O)[C@H](O)[C@H]2O)cc2c(c1O)C(=O)c1c(cc(C)c(O)c1OC)C2=O</smiles>

Gluco-aurantioobtusin (8)<smiles>COc1c(O)cc2c(c1O)C(=O)c1c(cc(C)c(O)c1OC)C2=O</smiles>

Aurantio-obtusin (10)<smiles>COc1cc2c(c(OC)c1OC)C(=O)c1c(cc(C)c(OC)c1OC)C2=O</smiles>

Chryso-obtusin (11)<smiles>COc1cc2c(c(O)c1OC)C(=O)c1c(cc(C)c(O)c1OC)C2=O</smiles>

Obtusin (12)<smiles>COc1c(O)c(C)cc2c1C(=O)c1c(O)cccc1C2=O</smiles>

Obtusifolin (13)<smiles>COc1cc(O)c2c(c1)C(=O)c1cc(C)cc(O)c1C2=O</smiles>

Physcion (14)<smiles>O=C(O)c1cc(O)c2c(c1)C(=O)c1cccc(O)c1C2=O</smiles>

Rhein (15)

Figure 1. Two-dimensional chemical structures of flavonoids from Cassia tora (Kim et al., 2004; 2015; Shukla et al., 2018; Vijayalakshmi and Madhira, 2014). 
Table 2. Binding free energies of the 15 flavonoids toward the 15 anti-psoriatic protein targets.

\begin{tabular}{ccccccccc}
\hline Codes & TNF- $\boldsymbol{\alpha}$ & $\mathbf{A A}_{2} \mathbf{R}$ & P38MK & IL-23 & S1PR & PK & BTK & PAD \\
\hline NL & -10.80 & -12.62 & -12.32 & -11.91 & -17.36 & -14.68 & -13.26 & -13.91 \\
1 & -11.73 & -14.67 & -17.37 & -10.38 & -17.96 & -14.71 & -14.34 & -15.92 \\
2 & -12.27 & -13.78 & -15.30 & -11.18 & -18.24 & -16.24 & -15.51 & -15.06 \\
3 & -10.23 & -12.72 & -13.57 & -9.95 & -16.69 & -13.14 & -13.01 & -13.52 \\
4 & -9.70 & -12.71 & -15.15 & -8.82 & -14.47 & -12.95 & -13.28 & -13.01 \\
5 & -9.97 & -11.31 & -12.70 & -9.31 & -13.39 & -12.18 & -11.33 & -11.43 \\
6 & -7.73 & -9.60 & -10.17 & -5.92 & -10.24 & -10.15 & -9.60 & -9.42 \\
7 & -9.88 & -13.48 & -15.59 & -9.87 & -15.94 & -13.45 & -13.25 & -12.95 \\
8 & -12.26 & -17.36 & -16.29 & -9.93 & -18.25 & -15.60 & -15.20 & -15.67 \\
9 & -11.92 & -14.57 & -14.54 & -9.62 & -16.91 & -13.88 & -14.83 & -14.25 \\
10 & -10.69 & -14.63 & -16.43 & -9.84 & -15.90 & -14.94 & -14.34 & -13.11 \\
11 & -10.27 & -13.75 & -16.23 & -8.12 & -15.19 & -13.60 & -12.60 & -12.60 \\
12 & -10.68 & -14.71 & -18.17 & -10.92 & -16.07 & -15.65 & -13.60 & -14.65 \\
13 & -10.04 & -12.86 & -14.43 & -8.52 & -15.39 & -14.28 & -12.32 & -12.95 \\
14 & -10.83 & -12.74 & -14.06 & -9.54 & -13.77 & -13.76 & -12.68 & -12.74 \\
15 & -11.07 & -15.08 & -16.05 & -8.50 & -15.83 & -13.15 & -13.57 & -13.62 \\
\hline
\end{tabular}

\begin{tabular}{cccccccc}
\hline Codes & SPK & PKC & IL-17A & PDE-4 & CCS & JAK-3 & RAC1 \\
\hline NL & -13.02 & -12.23 & -10.59 & -12.28 & -11.65 & -9.73 & -16.08 \\
1 & -16.42 & -14.43 & -13.84 & -15.68 & -13.45 & -14.96 & -17.90 \\
2 & -15.21 & -15.22 & -14.80 & -16.77 & -16.16 & -15.14 & -17.40 \\
3 & -12.86 & -14.15 & -11.26 & -14.41 & -14.29 & -13.82 & -15.84 \\
4 & -13.17 & -12.62 & -11.52 & -13.02 & -12.52 & -13.17 & -14.02 \\
5 & -12.12 & -11.97 & -10.37 & -12.58 & -11.86 & -12.48 & -12.97 \\
6 & -9.59 & -9.63 & -7.51 & -10.02 & -8.76 & -9.25 & -10.18 \\
7 & -12.87 & -13.29 & -11.22 & -14.63 & -12.24 & -13.11 & -13.78 \\
8 & -14.78 & -14.47 & -12.60 & -18.49 & -13.33 & -16.00 & -16.17 \\
9 & -13.93 & -14.78 & -11.82 & -15.09 & -15.40 & -13.72 & -15.38 \\
10 & -14.44 & -13.97 & -12.68 & -15.47 & -13.27 & -13.36 & -14.93 \\
11 & -13.65 & -12.48 & -11.40 & -14.48 & -12.04 & -12.41 & -14.36 \\
12 & -14.16 & -13.24 & -12.64 & -15.19 & -13.46 & -13.19 & -14.22 \\
13 & -13.00 & -13.22 & -11.70 & -13.57 & -13.50 & -13.14 & -13.55 \\
14 & -13.19 & -13.04 & -11.68 & -13.26 & -12.22 & -12.71 & -13.69 \\
15 & -13.57 & -13.55 & -12.12 & -15.87 & -13.05 & -13.09 & -14.54 \\
\hline
\end{tabular}

\section{Docking calculations}

The free binding energies of each of the studied flavonoids from Cassia tora towards 15 selected antipsoriatic drug targets and the number that bound to the proteins stronger than the co-crystallized ligands are shown in Table 2 and Figure 2, respectively. It was observed that all the flavonoids made varying degrees of favorable interactions with each of the protein targets. London dG scoring method identified that five compounds had a higher binding affinity toward tumor necrosis factor- $\alpha(\mathrm{TNF}-\alpha)$,
Bruton's tyrosine kinase (BTK), peptidyl arginine deiminases (PAD), and spleen protein kinase (SPK) than their native ligands. Twelve of the flavonoids made better interactions with $\mathrm{AA}_{2} \mathrm{R}, \mathrm{PK}$, and protein kinase $\mathrm{C}$ (PKC) than their co-crystallized inhibitors, whereas all the compounds except 6 had lower free binding energy toward P38MK, interleukin (IL)-17A, phosphodiesterase-4 (PDE4), cathepsin S (CCS), and Jak-3 than their native ligands. Only the docking scores of 1,2 , and 8 were lower than the reference ligands of S1PR and Rac1. 


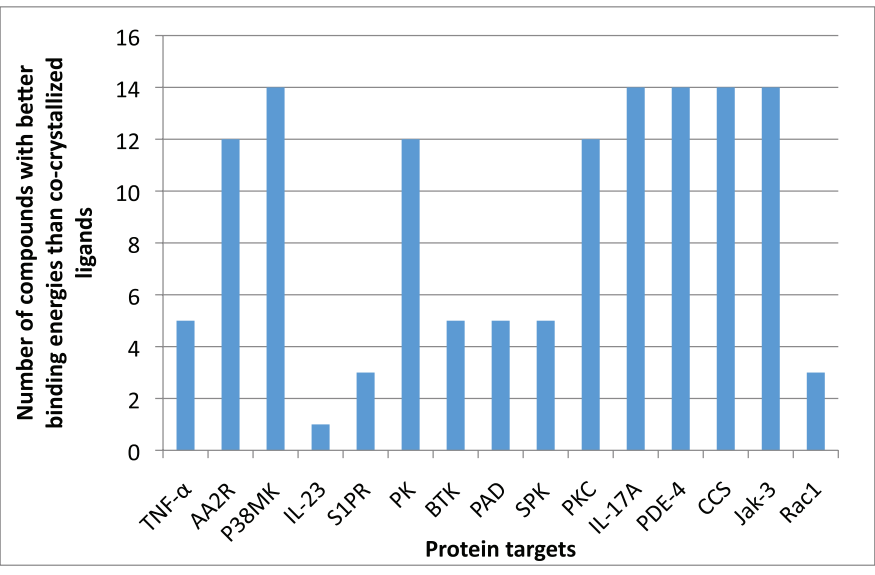

Figure 2. The distribution of the number of compounds with better binding energies toward the studied protein targets than the co-crystallized ligands.

TNF- $\alpha \quad(\mathrm{PDB}-2 \mathrm{AZ} 5) ; \quad \mathrm{A}_{2} \mathrm{AR} \quad(\mathrm{PDB}-2 \mathrm{YDO})$ adenosine receptor; $\mathrm{p} 38 \mathrm{MAPK}$ (mitogen-activated protein kinase p38); IL-23 (PDB-3QWR) interleukin-23; SIPR (PDB-3V2W) sphingosine 1-phosphate receptor; BTK (PDB4OTF) Bruton's tyrosine kinase; PAD (PDB-4X8G) peptidyl arginine deiminases; SPK (PDB-4XG6) spleen protein kinase; PKC (PDB-5F9E) protein kinase C; IL-17A (PDB-5HI4) interleukin 17A; PDE-4 (PDB-5K1I) phosphodiesterase-4; CCS (PDB-5QC5) cathepsin S; JAK-3 (PDB-5TTS) Janus kinase; RAC-1 (PDB-5VCU) Ras-related c3 botulinum toxin substrate 1 . NL represents native (co-crystallized) ligands which differ per protein target.

Moreover, it was noted that only two interacted with IL-23 with a binding affinity comparable to its native ligand. The docking score results of the studied flavonoids highlight the presence of a highly polar group (especially sugar) as a vital structural requirement for strong binding with the target proteins. Besides, the protein targets seem to form a complex with pyranone bearing molecules more favorably than the diones. The validity of the suggested structureactivity relationship is predicated on the observed reduction of binding affinity on replacing the two hydroxyl groups of 1 with hydrogen and methoxyl group (3). Furthermore, the improved polarity due to the presence of carboxylic acid group on C-6 of the sugar moiety of 2 , accounts for its enhanced interaction with the protein targets over 1, 3, 8, and 9 (which also have sugar moiety). Again the relatively very weak binding interaction of 6 , which contains the least number of polar groups, with the studied protein targets, goes to underscore the importance of lipophilic groups to binding with the protein targets (Figure 3). Worthy of note is the contribution that the possible pi-pi bonding existing between the aromatic rings of the flavonoids and the Phe28 has on the target-ligand formation and stability. The physicochemical features of the flavonoids from the plant are shown in Table 1 Lipinski rule proposed a molecule will be drug-like if it has MW of less than 500, the lipophilicity of less than 5, and hydrogen bond acceptor/donor of less than 10/5, respectively (Lipinski, 2000). None the less, the rule accommodates compounds that violate the maximum of two of the criteria. Therefore, all the studied flavonoids from Cassia tora are orally bioavailable and hence account for the ease of their absorption from the plant extract. Out of the flavonoids from Cassia tora, we consider 1, 2 and 8 as the candidates that worthy of further consideration, particularly because they bound more strongly to all the 15 studied antipsoriatic targets, except IL-23. Taken together, this study indicates that not only fatty acid but also flavonoid content of Cassia tora contributes to the antipsoriatic property of the plant. Therefore, scientists are encouraged to explore the flavonoid family in search for new and better antipsoriatic agents. a

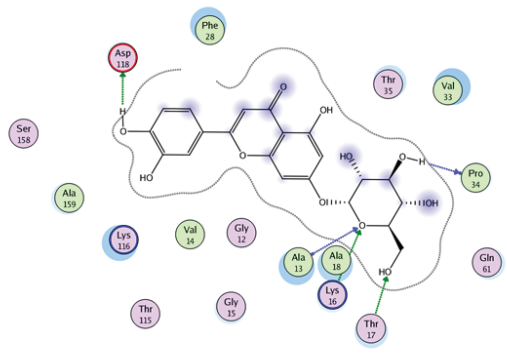

C

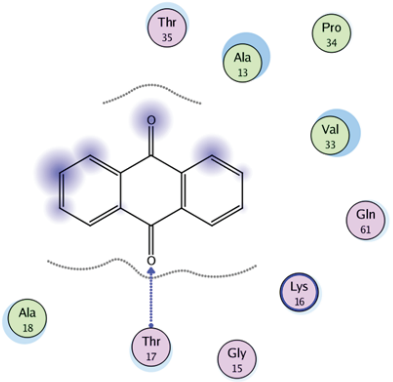

b

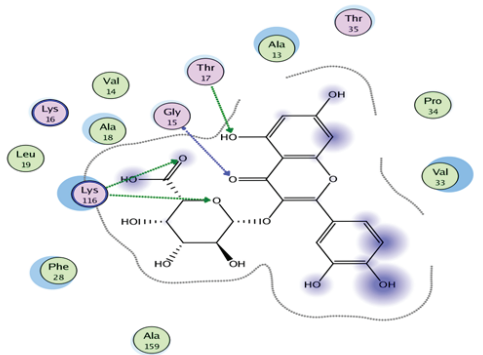

d

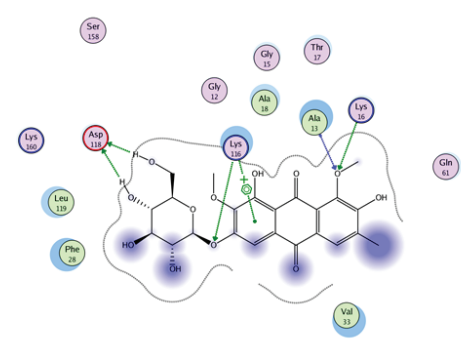

Figure 3. Binding interaction of 1 (a), 2 (b), 6 (c), and 8 (d) with the active site amino acid residues of Rac1. 


\section{CONCLUSION}

All the 15 flavonoids identified from the plant were found to obey all the criteria of Lipinski's rule of five for druglikeness with the exception of three compounds with two Lipinski violations. In addition, all the flavonoids interacted with 15 selected validated anti-psoriatic drug targets at very degrees. The same three with two Lipinski violations ranked higher than the individual co-crystallized ligands for the studied protein targets, except IL-23. Moreover, analysis of the binding interaction suggests that structural bulkiness and present of polar groups are essential for favorable binding contact across the entire considered anti-psoriatic protein target. Given the physicochemical features of the three flavonoids $(1,2$, and 8$)$ and their interesting binding interactions with all the antipsoriatic protein targets, further attention on them is advised to exploit their potentials as revealed in this study for the advancement of anti-psoriatic drug development and the communal knowledge of anti-psoriatic science as a whole.

\section{ACKNOWLEDGMENTS}

Dr. F. Ntie-Kang of Chemical and Bioactive Information Center, University of Buea, Cameroon, is acknowledged for computational support.

\section{CONFLICT OF INTEREST}

The authors declared no conflict of interest.

\section{FINANCIAL SUPPORT}

None.

\section{REFERENCES}

Berman HM, Westbrook J, Feng Z, Gilliland G, Bhat TN, Weissig H, Shindyalov IN, Bourne PE. The protein data bank. Nucleic Acids Res, 2001; 28:235-342.

Bowcok AM. The genetics of psoriasis and autoimmunity. Ann Gennomics Hu Genet, 2005; 6:93-122.

Cathrine L, Prabavathi N. Preliminary phytochemical analysis and antibacterial activity of leaf extract of vitex leucoxlon 1.f. Int J Curr Pharm Res, 2011; 13:71.

Chemical Computing Group Inc. Molecular operating environment version 2010. Montreal, Canada, 2010.

Christopher E, Steny W. Psoriasis. In: The Fitzpatrick, Eisen AZ, Wolff K (Eds.). Dermatology in general medicine. McGraw Hill, New York, NY, pp 489-515, 1993.

Darvas F, Keseru G, Papp A, Dormán G, Urge L, Krajcsi P. In silico and ex silico ADME approaches for drug discovery. Curr Top Med Chem, 2002; 2:1287-304.

Dictionary of natural products on CD-rom. Chapman and Hall/ CRC Press, London, UK, 2005.
Griffiths CE, Barker JN. Pathogenesis and clinical features of psoriasis. Lancet, 2007; 370:263-71.

Halgren TA. Merck molecular force field. J Comput Chem, $1996 ; 17: 490-641$

Ibezim A, Onyia K, Ntie-Kang F, Nwodo NJ. Drug-like properties of potential anti-cancer compounds from Cameroonian flora: a virtual study. J App Pharm Sci, 2015; 5(06):133-7.

Kim M, Lim JS, Lee HJ, Nho CW. Cassia tora seed extract and its active compound aurantio-obtusin inhibit allergic responses in IgEmediated mast cells and anaphylactic models. J Agric Food Chem, 2015; 63:8262-6.

Kim Y, Lee CH, Kim HG, Lee HS. Anthraquinones isolated from Cassia tora (leguminosae) seed show aan antifungal property against phytopathogenic fungi. J Agric Food Chem, 2004; 52:6096-100.

Lipinski CA. Drug-like properties and the causes of poor solubility and poor permeability. J Pharmacol Toxicol Methods, 2000; 44:235-49.

Ntie-Kang F, Nwodo NJ, Ibezim A, Simoben CV, Karaman B,Ngwa FV, Sippl W, Adikwu MU, Mbaze ML. Molecular modeling of potential anticancer agents from African medicinal plants. J Chem Inf Model, 2014; 54:2433-50.

Scott WRP, Hunenberger PH, Tironi IG, Mark AE, Bileter SR, Fennen J, Torda AE, Huber T, Kruger P, vanGunsteren WF. The GROMOS biomolecular simulation program package. J Phys Chem, 1999; 103:3596607.

Shukla S, Hegde S, Kumar A, Chaudhary G, Tewari SK, Upreti DK, Pal M. Fatty acid composition and bacterial potential of Cassia tora (leaves and stem) collected from different geographical areas of india. J Food Drug Anal, 2018; 26:107-11.

Tollefson MM, Van Houten HK, Asante D, Yao X, Maradit Kremers H. Association of psoriasis with comorbidity development in children with psoriasis. J Amer Med Assoc Dermatol, 2018; 154:286-92; doi:10.1001/jamadermatol.2017.5417.

Vijayalakshmi A, Madhira G. Anti-psoriatic activity of flavonoids from cassia tora leaves using the rat ultraviolet $\mathrm{B}$ ray photodermatitis model. Rev Bras Farma Elsevier Editorial Ltd, 2014; 24:322-9.

How to cite this article:

Akachukwu I, Amara EE. In-silico study of flavonoids from Cassia tora as potential anti-psoriatic agent. J Appl Pharm Sci, 2019; 9(04):082-087. 